\title{
Research on the Integration and Development of College Physical Education and College Students' Core Quality
}

\author{
Xiang Jinxing
}

\author{
Sports Department of Shenyang City University, Liaoning, Shenyang, 110112, China \\ *Corresponding author. Email: 346134029@qq.com
}

\begin{abstract}
Keywords: sports activities, students, mental health

\section{INTRODUCTION}

Health is the core component of modern health in modern society. In the process of physical education teaching, we must start from the perspective of health, and every physical education teacher must uphold the concept of health first and constantly attach importance to the mental health of students. And with the continuous development of society, students' mental health has become the focus of attention in the field of education. For students' mental health, physical education teachers need to use the corresponding teaching methods and methods scientifically and reasonably from the perspective of physical activities in the actual teaching process. Meanwhile, they also need to update and develop their own education concepts to better carry out the education to promote students' mental health and further enable students to grow up healthily.
\end{abstract}

With the continuous reform of education, schools and parents pay more attention to the all-round development of students' moral, intellectual, physical, aesthetic and labor. In this context, more schools and parents pay attention to physical education, especially teaching in physical education classroom. For students, physical activity is not only a kind of physical exercise, but also a kind of psychological activity, which is the effect of the combination of body and psychology. Physical activities for students can not only exercise, but also promote the mental health of students. As we all know, the traditional physical education curriculum is setting up by the purpose which comes from the perspective of students' physical health to physical activities, but it is not enough attention for students' mental health, and even some physical education teachers do not care about the impact of physical activities on students' mental health. From the perspective of sports activities, this paper explores how to use sports activities to promote students' mental health in the process of sports teaching, so that students can have a better mental state for growth and learning.

\section{Practice the provisions of the new curriculum standard, and constantly integrate into the students' sports activities from their own initiative}

\subsection{Understand students' views on sports activities from the perspective of new curriculum standards}

\footnotetext{
In the process of traditional physical education, students have a very contradictory psychology for physical education. Many students like physical activities, but they don't like physical education courses, while some students are not willing to carry out physical activities, or even very negative to physical education courses. The main reason for this phenomenon is that students have a vague understanding of the development and change of many things, and the understanding of sports activities is not clear enough. From the perspective of students, they think that they are healthy without physical activities, and many students will think that physical education is unnecessary [1]. There is a more important reason is that when students carry out sports activities, if they can't complete the action, they will be laughed at by their classmates, so that students will only have a certain fear and fear of sports activities, and lose interest in sports activities. While many teachers basically adopt the traditional teaching method when they
} 
are teaching. They pay more attention to the mastery of students' sports skills in physical education. However, they do not pay enough attention to the cognitive and physical aspects of sports, or even ignore students' emotions and interests. In pe class, many pe teachers are not good at communicating with students. They can only teach pe according to their own ideas, which makes students lose interest in pe course.

\subsection{Analysis of new curriculum standard and students' participation in sports activities}

With the new provisions of the new curriculum standards for the cultivation of students' mental health, pe teachers must take a variety of sports activities to educate students in mental health from the perspective of students. And with the continuous reform of education, physical education teachers should constantly change their teaching concepts. Therefore, as a physical education teacher, we must start from the basic concept of the new curriculum standard to constantly regulate the new curriculum standard, change our teaching concept in time, and add more physical education activities in the classroom according to the students' physical conditions and interests. More importantly, according to the advantages and characteristics of students, constantly change their own teaching methods, so as to promote the healthy growth of students. In modern society, schools pay more and more attention to physical education, so physical education teachers must seize the opportunity to change students' one-sided or wrong understanding of sports activities through a variety of sports competitions, and constantly cultivate students' interest in sports activities. At the same time, they should respect each student's personality differences and development in sports classes. When the students must be afraid in physical education, the teacher must eliminate the students' fear and fear in time according to the students' situation [2]. In the usual accumulation, teachers also need to know more books about physical education and mental health, so that when they are in physical education class, they can let students really know what is mental health and know more about mental health, which is a beneficial effect on physical health, so that students can pay more attention to their own mental state, and only let students really know their own mental state at the same time, students can make better use of sports activities to promote their mental health. At the same time, the teacher must join in the physical activities of the students when carrying out the actual teaching to be able to join with the students, break, eliminate the strangeness between the teacher and the students, better enter the inner world of the students, accept everything from the psychological level, and constantly shorten the distance between the students and the teachers, so that the students can have a deeper understanding of the physical activities ardently love.

\section{GRASP THE PROCESS OF PHYSICAL EDUCATION BASED ON THE CHARACTERISTICS OF PHYSICAL EDUCATION AND TEACHING MATERIALS}

\subsection{Understanding of the characteristics of physical education in depth}

The teaching material of physical education contains a lot of mental health factors, which can better promote the development of students' mental health. At the same time, many learning objectives and contents involved in the course can promote students' mental health. And is participating in a lot of sports activities in the process can experience a lot of sports spirit, more can promote the cultivation and development of students' mental health. Some ball games can cultivate students' spirit of cooperation and team consciousness. In the process of ball games, students can cultivate better tacit understanding with other students, and help each other in sports activities and learning. In the actual teaching process of physical education, if we want to achieve the goal of mental health, we must design relevant activities in physical activities, so that students can get better physical experience in this activity situation[3].

\subsection{Create suitable sports activities for students from the point of view in sports teaching materials}

Therefore, pe teachers must be able to create more scientific and reasonable situations from the perspective of students according to the characteristics of pe teaching materials and teaching, and students can freely learn pe activities in the settings. For example, in the actual teaching process, teachers can make use of some story situations, language situations and venue situations to let students truly feel the experience brought by a kind of physical activity. When the teacher describes some situations set by himself, the students will automatically associate these situations, and then they will have certain inner feelings and emotional experience. The students will have a strong sense of role experience and strong interest in sports activities. To a certain extent, students will eliminate strangeness and certain psychological barriers in sports activities and participate in sports activities.

In the classroom of physical education, teachers must fully grasp the time of students' autonomous activities, because autonomous activities are very important for students. They can let students choose their favorite sports freely according to their own interests and different needs, so that students can form the idea of lifelong exercise in such subconscious knowledge and habits, and constantly enhance the ability of students to think independently [4]. At the same time, in the process of independent activities, students can also feel a sense of being the master in the learning process, so that students can better learn more sports activities. For example, 
in some sports exercises, teachers should choose more exercise forms and let students choose a variety of exercise items. At the same time, when teaching physical education, teachers should try their best to choose some sports activities that students are interested in, and sports activities should have new ideas, which can arouse students' curiosity.

\subsection{Pay attention to ordinary sports activities according to the characteristics of sports discipline}

In the process of the ordinary sports meeting, the school should also hold more events that interest students. In addition to some traditional track and field competitions, it can also arrange some interesting events to expand the participation of students, so as to really enjoy sports activities. No matter in the physical education class or in the sports meeting, the school and the teacher should give the students more choices, give the students more respect, and constantly mobilize the enthusiasm of the students, so that the students can continuously try and experience in the process of independent activities and find the fun of sports activities with their own ideas and efforts. In short, sports activities are a stage for students to show themselves and express themselves, and a process experience in sports activities. For students, it is not only an experience of success, but also an experience of failure, so teachers must arrange sports activities reasonably according to students' psychological characteristics. In the actual sports activities, we should not only let students feel some successful experience, but also let students get some failure experience. When students have a successful experience, they can constantly improve their self-esteem and self-confidence, thus forming a habit of physical exercise, and constantly cultivating their strong quality [5].

\subsection{Always pay attention to the feeling of students in sports activities and give timely help}

When students get failure and experience, self-confidence may be hurt and lose interest in sports learning. At this time, teachers need to be able to timely observe the state of students and take a better way to file students to let them face the difficulties, so as to really overcome the difficulties. In the actual process of sports activities, teachers should conduct reasonable guidance experience, so that students can truly and completely experience sports activities. Under such conditions, teachers should give full protection to students, and at the same time, they should be able to let students exercise themselves, because if teachers over protect or over indulge students, they will have psychological impact on students healthy growth has adverse effects, so teachers must master the degree of putting and receiving to enable students to learn selfmanagement.

\section{PROBLEMS ENCOUNTERED FROM STUDENTS IN SPORTS ACTIVITIES SOLUTIONS}

\subsection{Analysis of students' problems in sports activities}

In the actual teaching process, the teacher must consciously guide the students through the whole learning process of finding problems, analyzing problems and solving problems, and be able to practice sports knowledge and sports skills, so that students can get more real emotional experience in the process of sports activities. Teachers can carefully observe some problems encountered by students when they are engaged in physical activities, and effectively penetrate some mental health education in these problems, so that students can obtain more learning achievements in the learning process to further enhance their self-confidence in learning, so that students can have a better learning attitude to face future learning. When students have a good learning attitude, they will have a better attitude towards life, so as to achieve the goal of mental health education[6].

\subsection{Establish a new relationship between teachers and students to solve problems in Teaching}

In the traditional physical education teaching process, the biggest characteristic is that many teachers will use the command tone to let students do some physical activities, and students must obey the teacher's command, making the relationship between teachers and students more rigid, so that students have a certain degree of rebellious psychology. The most important point of using physical activities to promote students' mental health is to let students and teachers establish a more harmonious relationship between teachers and students. In the process of teaching, teachers must have full trust, students constantly face up to the psychological characteristics of students, from their own subjective consciousness to force students to do anything, at the same time, teachers must not hurt students' selfesteem, do not fully listen to each student's opinions, respect the rights of students. In addition, we should teach students in accordance with their aptitude according to their interests and hobbies, be good at discovering some excellent qualities and consciousness of students in sports activities, and constantly actively guide them, so that they can have more qualities, so as to provide certain conditions for their mental health growth [7].

Therefore, teachers must cultivate the feelings between teachers and students in the daily teaching process, and care and guidance for students can make students have trust in teachers. When organizing a physical activity, the teacher should pay attention to the feelings of each student after the physical activity, because the teacher can also see the students' views on the physical activity from these feelings [8]. When organizing sports activities, teachers must also let 
students have more autonomy, and truly let students become masters of classroom learning. No matter in physical education class or after class, teachers should learn more about students' new world and establish equal and democratic teaching atmosphere. In the actual teaching process, teachers should communicate with students with a very frank attitude, so that students can fully express their views, and at the same time, students can really feel the trust of teachers to students, so as to promote learning the mental health of students grows up.

\section{CONCLUSION}

In the process of education reform, the reform of physical education is very important. Similarly, physical education is a very important course for students. Therefore, teachers must keep up with the pace of the development of the times, constantly update their own teaching concepts, fully use the function of physical education, and constantly promote students' mental health. In the process of physical education, if teachers want to really promote students' mental health, they must start from the students' point of view, be able to really understand some of the students' psychological conditions, and then constantly change their own teaching methods and teaching characteristics, and effectively solve various problems encountered by students in physical activities, and further promote students' mental health, let students grow healthily. In the process of physical education, the psychology of teachers and students is in a dynamic process. The characteristics of physical education have a certain influence on the development of students' psychological health. Therefore, teachers must teach students according to their aptitude, constantly meet their physiological and psychological needs, and constantly hone their will in the process of physical education to train the students' sports spirit and enable them to develop healthily and wholeheartedly.

\section{REFERENCES}

[1] Ran Yaqiong. How to Promote Students' Mental Health Through Sports Activities [j]. Scientific Consultation, 2014 (30): 169-170

[2] Hu Xiaoqing. Improving Students' Mental Health Through Sports [j]. Science and Technology Information, 2011, 000 (001): 236

[3] Wang Zhenwen. An Analysis of the Promotion of Physical Education on the Mental Health Development of Police School Students [j]. Hope Monthly: Part 1 (11): 177-177

[4] Wu Junqing [1], Li Minguo [1]. How Can School Physical Education Promote the Development of Students' Mental Health [j]. Modern Primary and Secondary Education, 2007 (1)
[5] Wei Xingjiang, Liang Jianchun. Research on the Relationship Between Outdoor Sports Teaching and Promoting Students' Mental Health [j]. Contemporary Sports Technology, 2016, V.6; No.161 (11): 13-14

[6] Lin Hua, Guo Cong, Li Bing. The Sports Prescription of Extracurricular Sports Activities to Promote the Mental Health of College Students [j]. Journal of Shanxi Normal University, 2006, 21 (1): 8789

[7] Ma Jieping. Analysis of the Promotion of Physical Activities on the Mental Health of Primary School Students [j]. Examination Weekly, 2017 (35)

[8] Liu Jingzong. The Influence of Sports Activities on College Students' Mental Health [j]. Journal of Sports Science and Technology, 2010 (07): 89-90 + 104 